\title{
Trying to read: The "In Memorian" artwork
}

\author{
Keywords \\ Covid-19, Brazilian Federal Constitution, Data Visualization, Web art.
}

In this presentation we will analyze the multimedia artwork In Memorian, 2021, from the Research Group Realidades (School of Communication and Arts of University of São Paulo, ECA-USP, Brazil). The artwork is a web art that deals with the visualization of data from the coronavirus pandemic in Brazil. These data are appropriated from online databases and it works as the rule of loss of information from 1988's Brazilian Federal Constitution, Title II - Of Fundamental Rights and Guarantees. The text is fragmented proportionally to Brazilian population and, then, loses its information, pixel by pixel, according to the daily number of deaths by covid-19 in the country. The authors of this presentation are members of the Realidades Group, thus, this analysis will be filled with our creative processes, poetic motivations and the development phases of the artwork. In Memorian exposes the precarious situation of the democratic rights guaranteed by the mentioned article of the Brazilian constitution. Brazil couldn't control covid-19 pandemic. Researches pointed out that it was due to a series of omissions and failures by public managers, mainly the federal government. However, the democratic rights have been under attack for longer. Brazil's political scene has become dominated by openly conservative, "anti-politics" and "anti-science" wills, quite driven by desinformation and fake news. And all these relationships are fundamental to the development of the work. It seeks to materialize and illustrate hundreds of thousands of deaths in order to make visible the colossal size of human loss. The amount of deaths shatter the black words over the white background, damaging the text and making the reading more difficult. On the work's website, the text is exhibited in perspective and can be vertically scrolled. It also contains an interactive ruler that shows the Brazilian daily and total number of deaths, enabling the interactor to move across the timeline. The visual character of a 'monument for the dead' complaints the governmental negligence that causes this amount of suffering, actions that must not be simply forgotten. In addition, it points out the need for more transparency of covid's diagnosis and deaths registration and comments on the alarming political scenario that surrounds the sanitary crisis. Furthermore, this artwork is a data visualization piece, which is a very much explored technique used by multimedia artists. We will address its usage to enhances the visibility of things that are often hard to see. We will show another similar artwork in theme, 'Inumeráveis", 2020, created by a collective of volunteer artists and journalists. Claiming that "alive or dead, we will never be [just] a number", the site is an online monument that features shared stories about the victims, giving individuality to each of them. In Memorian was in the online exhibition EmMeio\#13 associated with the Panoramas 2021 event. Additionally, we point out its interaction in different social networks and its own numerical and online nature. The pandemic crisis in Brazil and around the world is not a past reality, still claiming countless lives. Unfortunately, the artwork remains operational. 